Supporting Information

\title{
Graphene quantum dot-based nanocomposites for diagnosing cancer biomarker APE1 in living cells
}

Hao Zhang, ${ }^{+}$Sai Ba, ${ }^{\ddagger}$ Zhaoqi Yang, ${ }^{\S}$ Tianxiang Wang, ${ }^{+}$Jasmine Yiqin Lee, ${ }^{\ddagger}$ Tianhu Li, ${ }^{*}$ and

Fangwei Shao ${ }^{*}$,

${ }^{\dagger}$ ZJU-UIUC Institute, Zhejiang University, Haining, Zhejiang 314400, China

Division of Chemistry and Biological Chemistry, School of Physical and Mathematical

Sciences, Nanyang Technological University, Singapore 637371, Singapore

${ }^{\S}$ School of Pharmaceutical Sciences, Jiangnan University, Wuxi, Jiangsu 214122, China

Corresponding Author:

*E-mail: fwshao@zju.edu.cn (F.S.)

*E-mail: thli@ntu.edu.sg (T.L.). 


\section{Materials}

Fluorophore-labelled AP site-containing oligonucleotides were synthesized by Sangon Biotech (Shanghai, China). Nucleotide sequences and modification details of these oligonucleotides are given in Table S1 and Fig. S1. Human apurinic/apyrimidinic endonuclease (APE1) for studies in cell-free systems and histone proteins were purchased from New England Biolabs (Singapore). The other DNA-related enzymes including DNA polymerase beta (POLB), DNA ligase 1 (LIG1), flap endonuclease 1 (FEN1), exonuclease 1 (EXO1), poly(A)-specific ribonuclease (PARN), human topoisomerase I (Topo I) and human topoisomerase II $\alpha$ (Topo II) were provided by Abcam, New England Biolabs, Novus Biologicals and TopoGEN, respectively. APE1 inhibitors used in this study were commercial products from Axon Medchem LLC (AR03 and APE1 Inhibitor III) and Sigma-Aldrich (CRT0044876). MCF-7, PANC-1 and MCF-10A cell lines were purchased from American Type Culture Collection (ATCC). Materials for cell culture and cell imaging experiments, including Dulbecco's Modified Eagle Medium (DMEM), fetal bovine serum, penicillin-streptomycin solution, trypsin (0.25\%), PBS buffer solution as well as CellMask Deep Red Plasma membrane Stain, NucBlue Live ReadyProbes Reagent, Lipofectamine RNAiMAX Transfection Reagent and Vybrant MTT Cell Proliferation Assay Kit were purchased from Thermo Fisher Scientific. Mammary Epithelial Basal Medium (MEBM) and MEGM SingleQuots Supplements were obtained from Lonza. The $35 \mathrm{~mm}$ dishes ( $\mu$-Dish with an ibidi polymer coverslip bottom) for confocal imaging were provided by ibidi GmbH and APE1 siRNA (SMARTpool: ON-TARGETplus APEX1 siRNA) was purchased from Dharmacon. Other chemicals used in this study (e.g. salts, buffers, electrophoresis reagents) were supplied by SigmaAldrich. 


\section{Supplementary Tables and Figures}

Table S1. Nucleotide sequences and modifications of oligonucleotides used in this study.

\begin{tabular}{|c|c|c|}
\hline Name & Nucleotide sequence (5' to $3^{\prime}$ ) & Modification \\
\hline Oligo 1 & $\begin{array}{l}\text { ATGTACTTCGGCTAATCTTCTAGAGGGTACCGGTCG } \\
\text { CGAAGCGACCGGTACC[AP site]TCTAGA }\end{array}$ & 3' Cy3 \\
\hline Oligo 2 & $\begin{array}{l}\text { ATGTACTTCGGCTAATCTTCTAGAGGGTACCGGTCG } \\
\text { CGAAGCGACCGGTACCCTCT[AP site]GA }\end{array}$ & $3^{\prime} \mathrm{Cy} 3$ \\
\hline Oligo 3 & $\begin{array}{l}\text { ATGTACTTCGGCTAATCTTCTAGAGGGTACCGGTCG } \\
\text { CGAAGCGACCGGTACCCT[AP site]TAGA }\end{array}$ & 3' Сy3 \\
\hline Oligo 4 & $\begin{array}{l}\text { ATGTACTTCGGCTAATCTTCTAGAGGGTACCGGTCG } \\
\text { CGAAGCGACCGGTA[AP site]CCTCTAGA }\end{array}$ & 3' Су3 \\
\hline Oligo 5 & $\begin{array}{l}\text { ATGTACTTCGGCTAATCTTCTAGAGGGTACCGGTCG } \\
\text { CGAAGCGACCGG[AP site]ACCCTCTAGA }\end{array}$ & $3^{\prime} \mathrm{Cy} 3$ \\
\hline Oligo $1 \mathrm{~A}$ & $\begin{array}{l}\text { ATGTACTTCGGCTAATCTTCTAGAGGGTACCGGTCG } \\
\text { CGAAGCGACCGGTACCCTCTAGA }\end{array}$ & 3' Су3 \\
\hline
\end{tabular}

Table S2. Particle size measurements and zeta potential determination of graphene quantum dots (GQDs) and Nanocomposite 1.

\begin{tabular}{lll}
\hline Sample name & Particle size $(\mathbf{d} . \mathbf{n m})^{\text {a) }}$ & Zeta potential $(\mathbf{m V})$ \\
\hline GQDs & $32.87 \pm 6.85$ & $-9.46 \pm 0.32$ \\
Nanocomposite 1 & $50.32 \pm 17.36$ & $-11.03 \pm 0.69$ \\
\hline
\end{tabular}

a) Particle sizes (in diameter) were measured by Dynamic Light Scattering (DLS) system. 
a.<smiles>COCC12CC(O)C(CC1(C)O)O2</smiles>

Hemiacetal

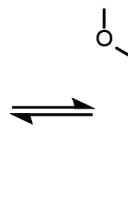

Aldehyde b.

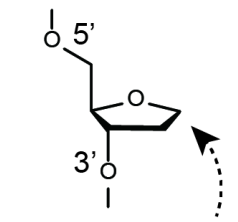

Without hydroxyl group

Figure S1. Structural comparison between uracil-DNA glycocasylase-generated AP sites and dehydroxyl AP site. (a) Molecular structures and chemical instability of uracil-DNA glycocasylase-generated AP sites and (b) molecular structures of chemically stable dehydroxyl AP site that is used in the current studies.
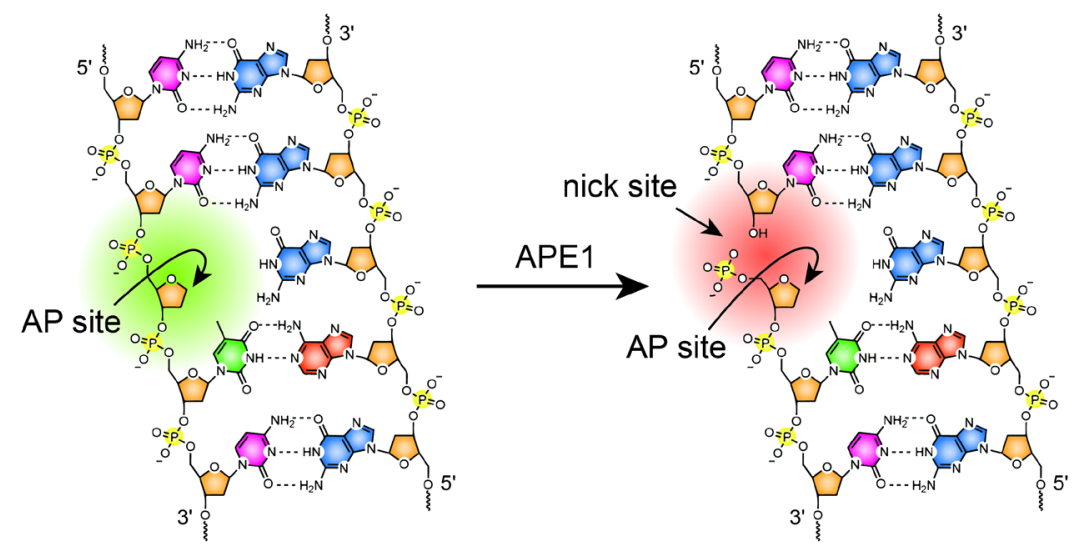

Figure S2. Molecular-scale view of APE1-mediated DNA cleavage at AP site of Unimolecular DNA 1 in Nanocomposite 1.

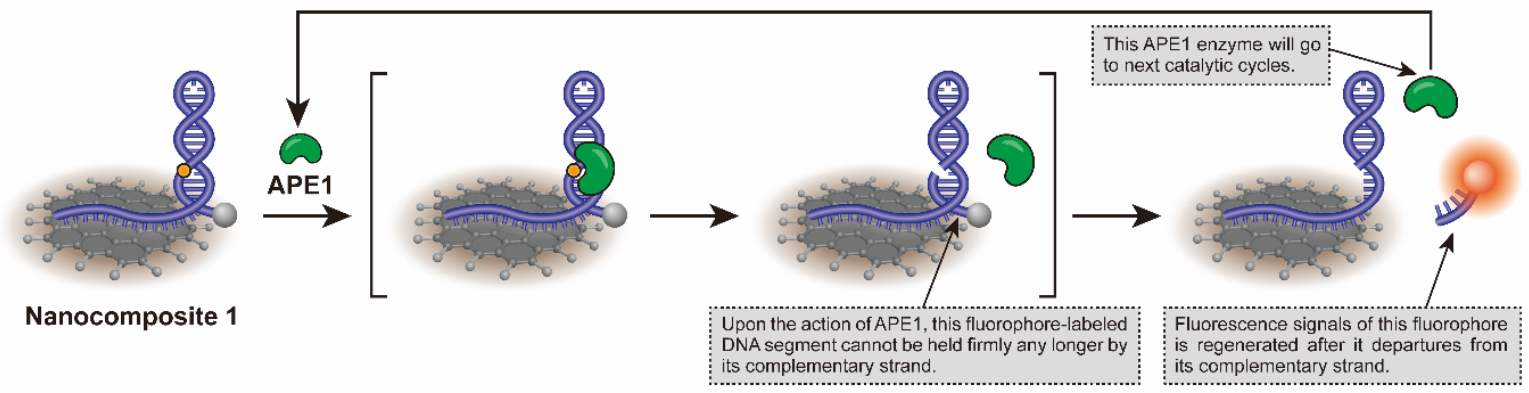

Figure S3. Schematic flow chart of the fluorescent response from Nanocomposite 1 to cellular APE1's enzymatic activity. 


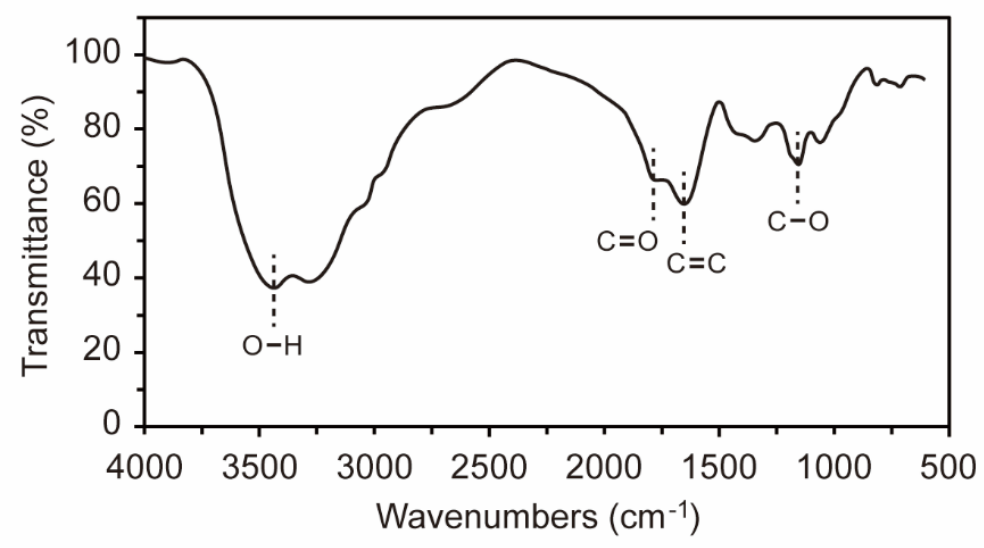

Figure S4. FTIR spectrum of graphene quantum dots.

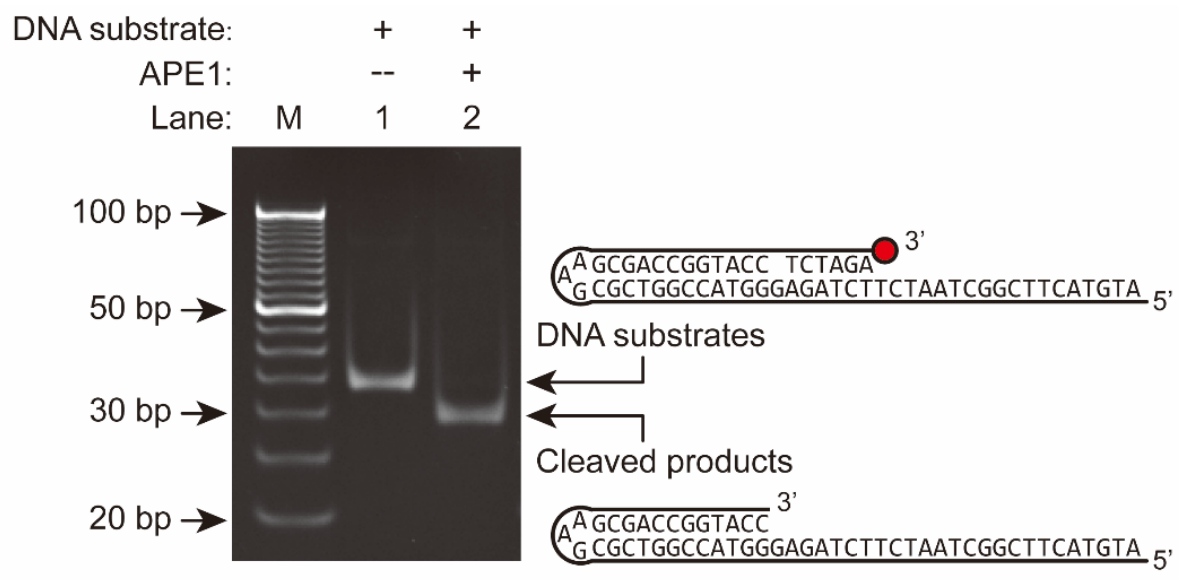

Figure S5. Gel electrophoresis confirmation of effectiveness of Unimolecular DNA 1 as APE1's substrate. M, O’RangeRuler 5 bp DNA Ladder; Lane 1, 100 nM of Unimolecular DNA 1 alone; Lane 2, a mixture of $100 \mathrm{nM}$ Unimolecular DNA 1 and $1 \mathrm{nM} \mathrm{APE} 1$ that was incubated at $37^{\circ} \mathrm{C}$ for $2 \mathrm{~h}$. Electrophoresis was performed using a $15 \%$ non-denaturing gel in Tris-boric-EDTA buffer at $10 \mathrm{~V} / \mathrm{cm}$ for $2 \mathrm{~h}$. 


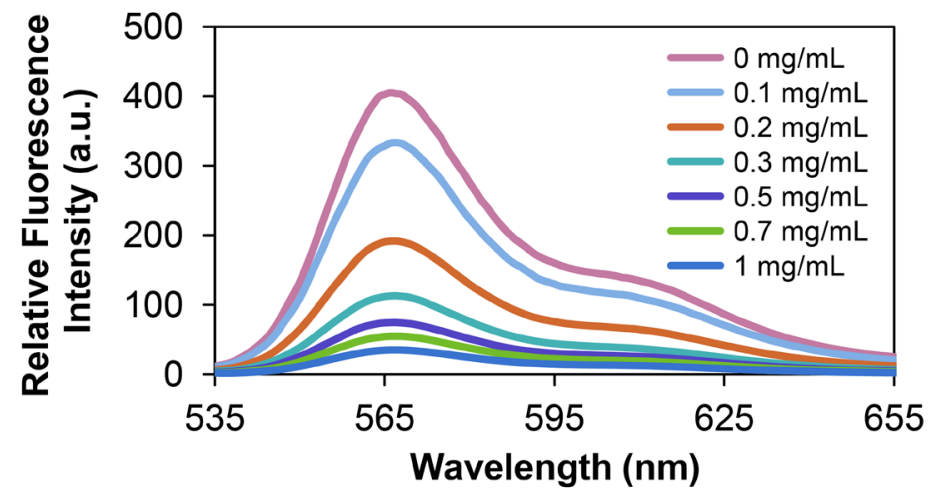

Figure S6. Decrease of fluorescence intensities in association with adsorption of fluorophorelabeled unimolecular DNA onto surfaces of graphene quantum dots. $100 \mathrm{nM}$ of Unimolecular DNA 1 was incubated with various concentrations of graphene quantum dots at $37^{\circ} \mathrm{C}$ for $2 \mathrm{~h}$ followed by fluorescent spectroscopic examination with excitation at $515 \mathrm{~nm}$. Observed low fluorescence intensities are indications that fluorescence signals of fluorophore-labeled unimolecular DNA are quenched owing to their adsorption onto surfaces of graphene quantum dots.

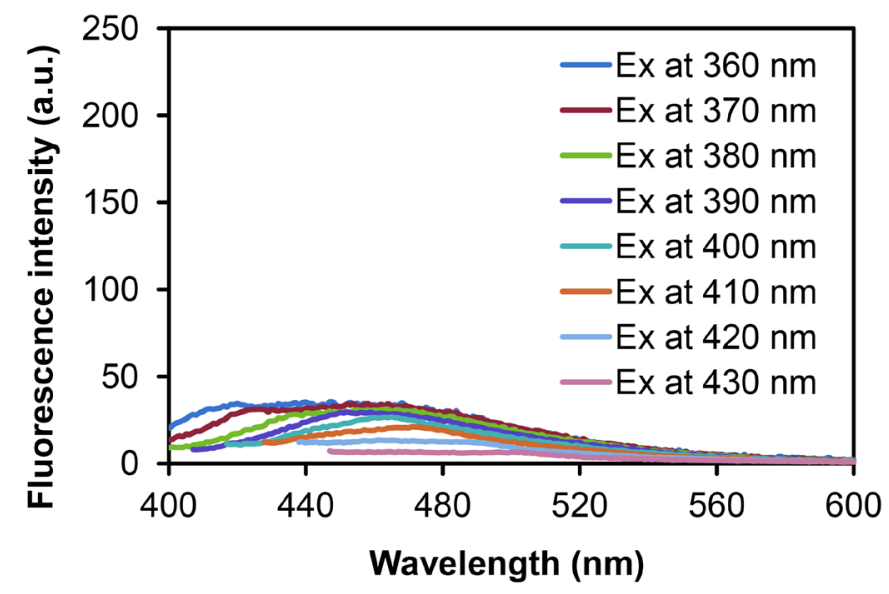

Figure S7. Fluorescence intensities of graphene quantum dots alone. Graphene quantum dots were prepared into aqueous solution in a concentration of $1 \mathrm{mg} / \mathrm{ml}$, whose fluorescence intensities were then measured at various excitation wavelengths. 


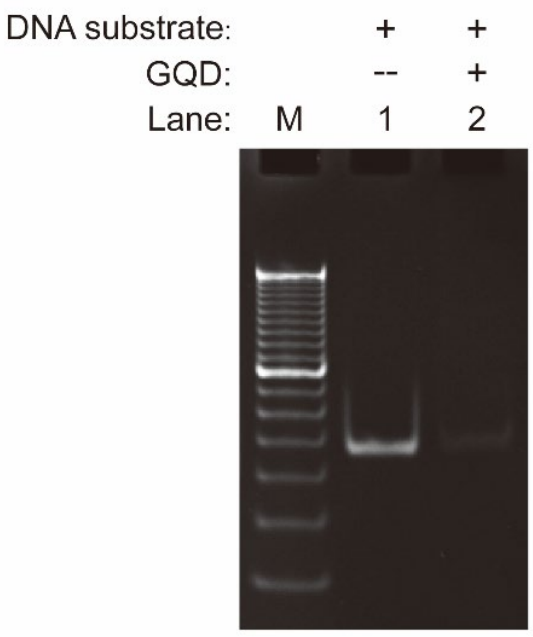

Figure S8. Gel electrophoretic analysis of the DNA-graphene quantum dot nanocomposites in comparison with the unimolecular DNA substrates. M, O’RangeRuler 5 bp DNA Ladder; Lane 1, $100 \mathrm{nM}$ of Unimolecular DNA 1 alone (DNA substrate); Lane 2, $100 \mathrm{nM}$ (DNA concentration) of DNA-graphene quantum dot nanocomposite (GQD). Electrophoresis was performed using a $15 \%$ non-denaturing gel in Tris-boric-EDTA buffer at $10 \mathrm{~V} / \mathrm{cm}$ for $2 \mathrm{~h}$, followed by ethidium bromide staining.

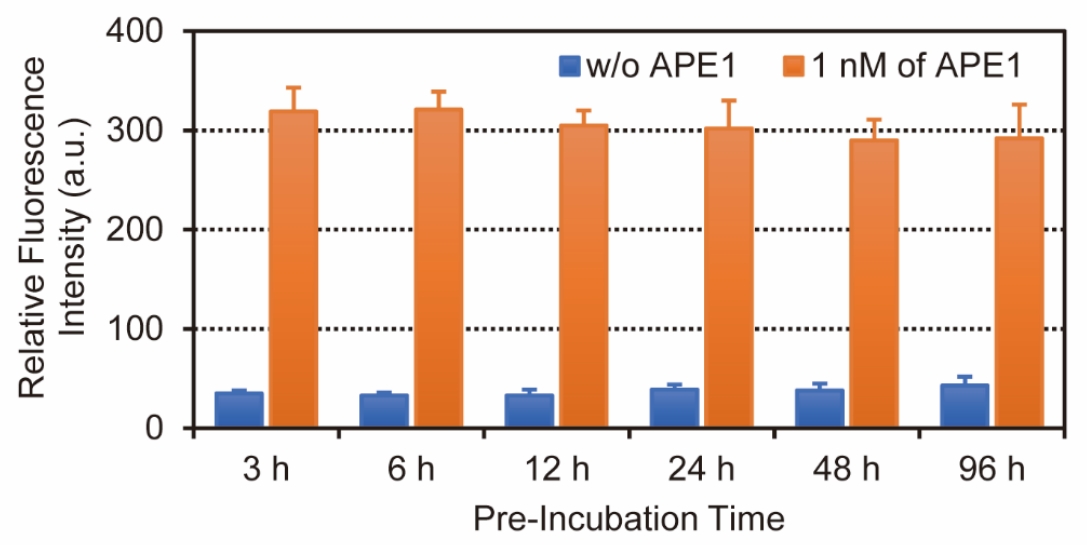

Figure S9. Examination of Nanocomposite 1's structural stability and sensing activity after preincubation at $37^{\circ} \mathrm{C}$ for various times. Nanocomposite suspensions (DNA concentration of 100 $\mathrm{nM}$ ) were pre-incubated in aluminum-foil-protected microcentrifuge tubes in the presence of 20 $\mathrm{mM}$ Tris-acetate ( $\mathrm{pH} 7.9), 50 \mathrm{mM}$ potassium acetate, $10 \mathrm{mM}$ magnesium acetate and $1 \mathrm{mM}$ DTT at $37^{\circ} \mathrm{C}$ for certain periods of time (blue bars) prior to the introduction of APE1 $(1 \mathrm{nM})$ and further incubation of 2 hours (orange bars). 
a.

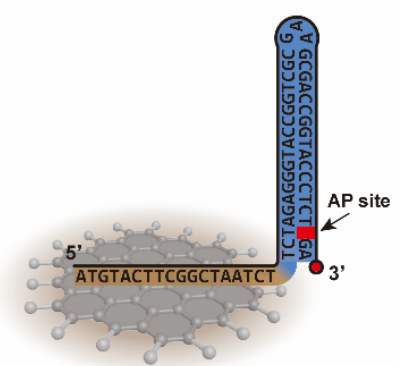

Nanocomposite 2

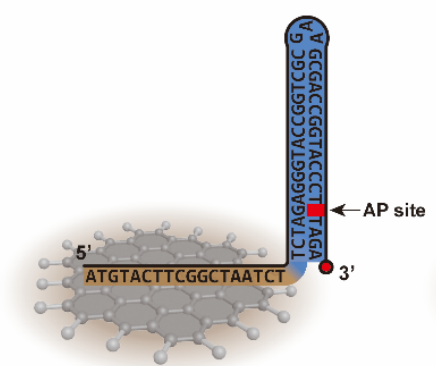

Nanocomposite 3

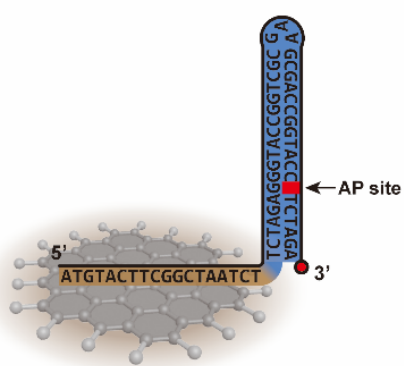

Nanocomposite 1

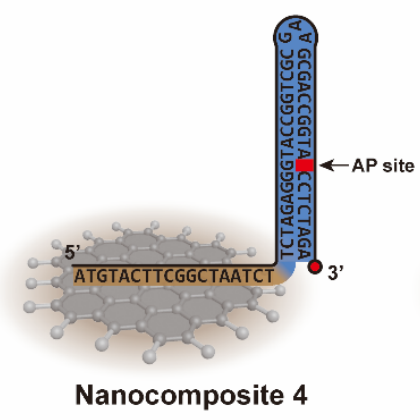

b.

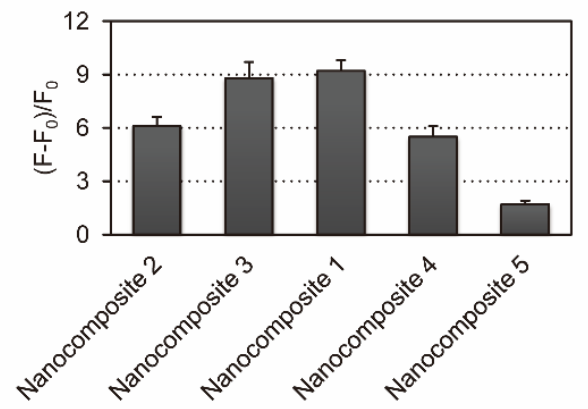

C.

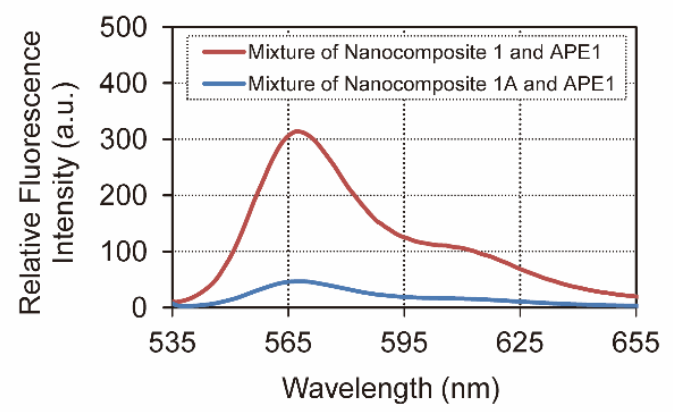

Figure S10. (a) Illustration of structures of Nanocomposites 1 to 5, in which AP sites appear at different locations in their unimolecular DNA components; and Nanocomposite 1A which contains no AP site in their unimolecular DNA components. (b) Relative fluorescence intensities of Nanocomposites 1 to 5 at an emission wavelength of $568 \mathrm{~nm}$ in their reactions with APE1. Data in this figure are representative of three independent experiments and values are expressed in mean \pm SD. (c) Fluorescence spectra of reaction mixtures of Nanocomposite 1A (blue) and reaction mixtures of Nanocomposite 1 (red) with excitation at $515 \mathrm{~nm}$. Samples for measurements of fluorescence intensities were carried out by incubating nanocomposites (DNA concentration of $100 \mathrm{nM}$ ) with $1 \mathrm{nM}$ of APE 1 at $37^{\circ} \mathrm{C}$ for $2 \mathrm{~h}$. 


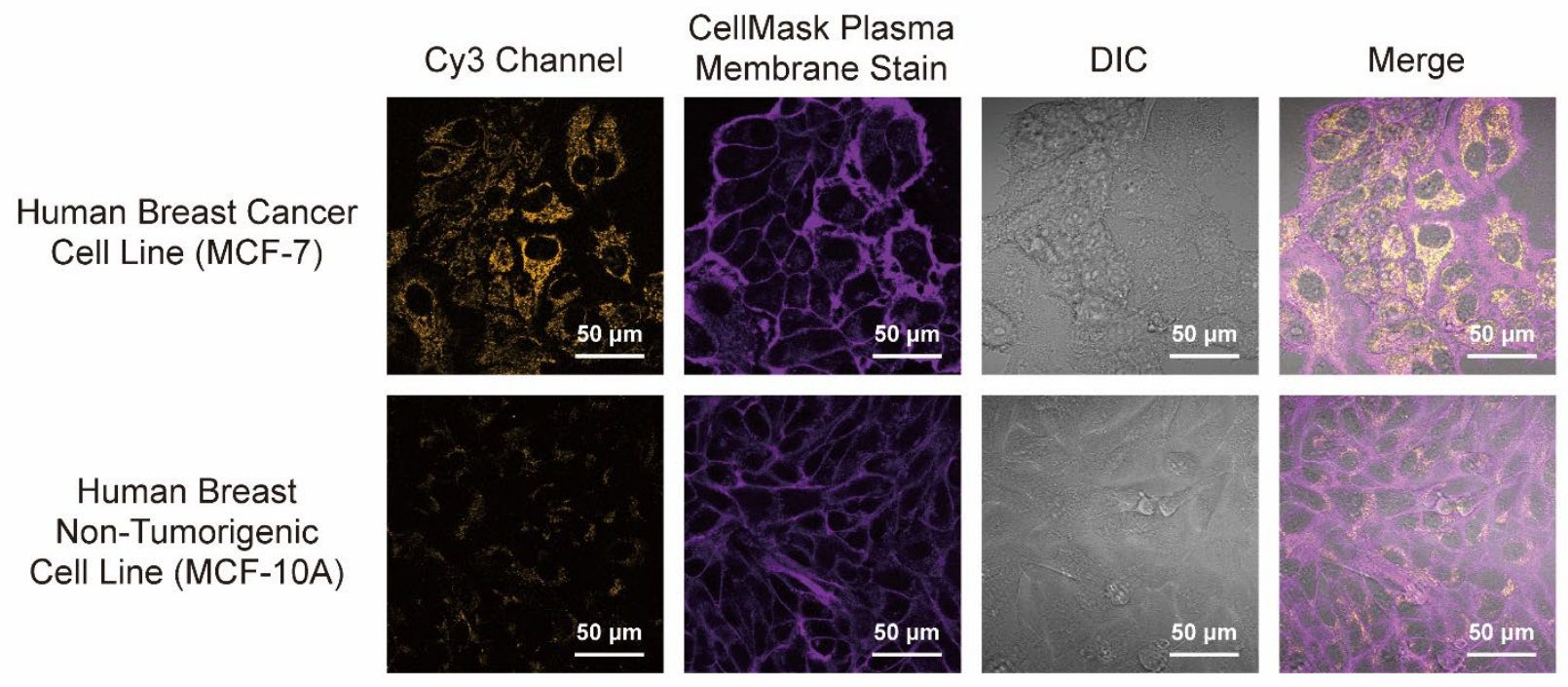

Figure S11. Confocal fluorescence microscopy images of human breast cancer cell line (MCF-7) and non-tumorigenic cell line (MCF-10A) that were pre-incubated with $100 \mathrm{nM}$ (DNA concentration) of Nanocomposite 1 at $37^{\circ} \mathrm{C}$ for $8 \mathrm{~h}$. Plasma membrane labelling using CellMask Plasma Membrane Stain was followed.

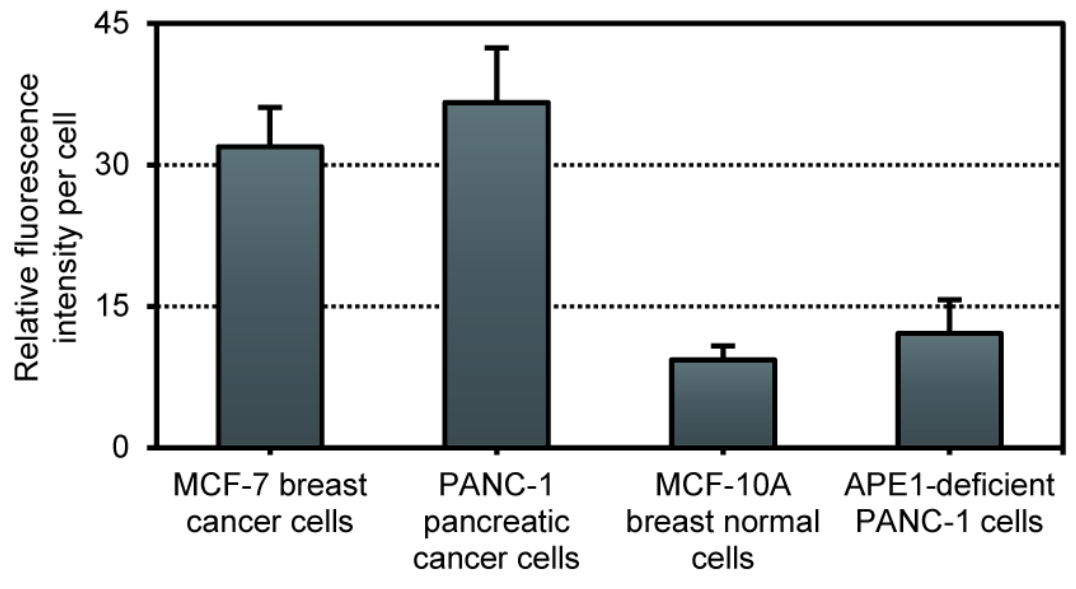

Figure S12. Quantitative analysis of APE1 expression levels in various types of human cell lines. Cells were incubated with $100 \mathrm{nM}$ (DNA concentration) of Nanocomposite 1 at $37{ }^{\circ} \mathrm{C}$ for $8 \mathrm{~h}$ followed by confocal microscopic analysis. Relative fluorescence intensity per cell were quantified from fluorescence microscopy images $(n=100$ cells) using ImageJ. 


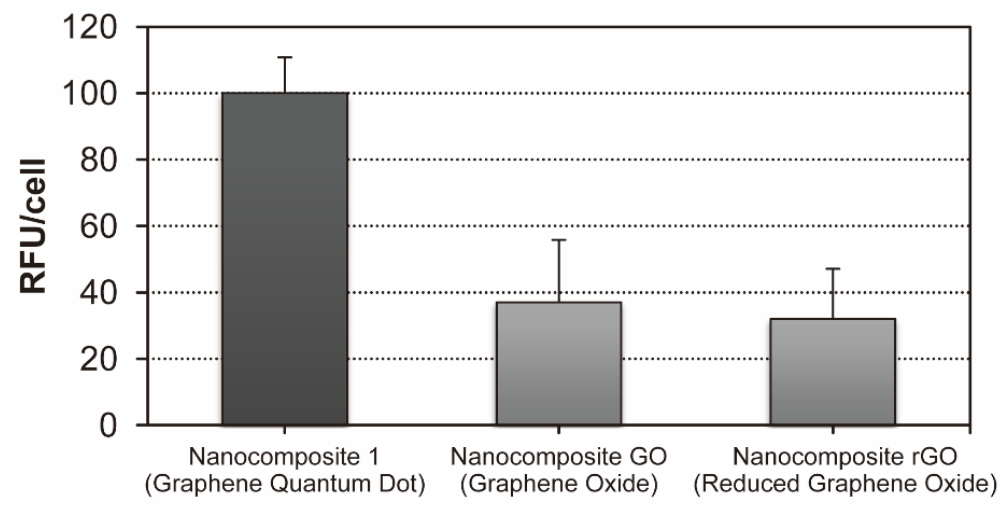

Figure S13. Comparison of cellular uptake efficiency of nanocomposites with the use of different nanomaterials as their carriers. Relative fluorescence units (RFUs) among PANC-1 cells were determined after incubation with graphene quantum dot-based nanocomposites (Nanocomposite 1), graphene oxide-based nanocomposites (Nanocomposite GO) and reduced graphene oxidebased nanocomposites (Nanocomposite $\mathrm{rGO}$ ) for $8 \mathrm{~h}$, respectively. Average intensities of fluorescence were quantified from confocal microscopy images $(n=100$ cells) using ImageJ. 